\title{
LANGUAGE AND COGNITION
}

\section{An interdisciplinary journal of language and cognitive science}
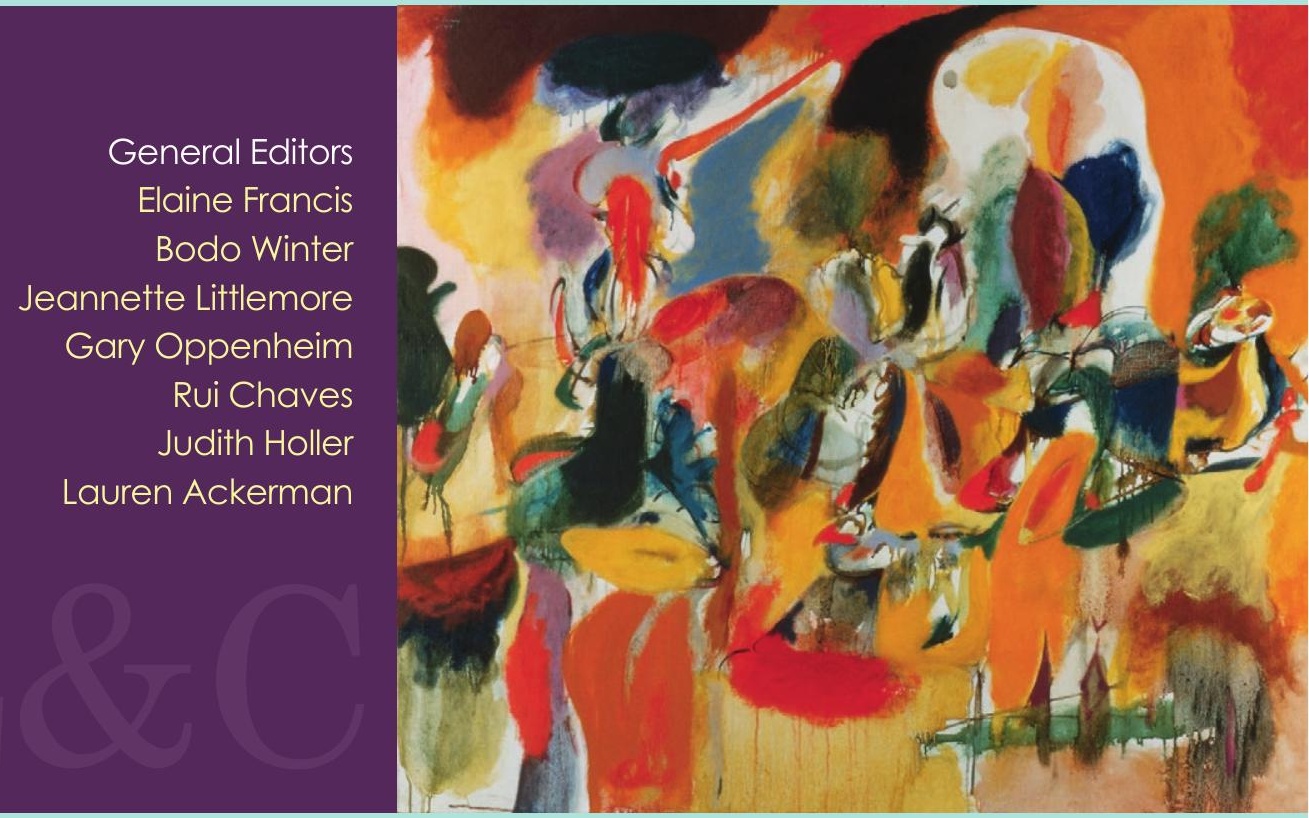

uk 


\section{LANGUAGE AND COGNITION}

\section{The Journal of the UK Cognitive Linguistics Association}

Language and Cognition is a venue for the publication of high quality peer-reviewed research of a theoretical and/or empirical/experimental nature, focusing on the interface between language and cognition. It is open to research from the full range of subject disciplines, theoretical backgrounds, and analytical frameworks that populate the language and cognitive sciences, on a wide range of topics. Research published in the journal adopts an interdisciplinary, comparative, multi-methodological approach to the study of language and cognition and their intersection.

\section{GENERAL EDITORS}

Dr Bodo Winter University of Birmingham, UK

Dr Elaine Francis

Purdue University, USA

Professor Jeannette Littlemore University of Birmingham, UK

\section{REVIEW EDITOR}

Dr Sarah Duffy

Department of Humanities

Northumbria University

Lipman Building

Newcastle upon Tyne

NE1 8ST, UK
Dr Gary Oppenheim

Bangor University, UK

Dr Rui Chaves

The State University of New York at Buffalo, USA

Dr Judith Holler

Radboud University, The Netherlands

Dr Lauren Ackerman

Newcastle University, UK

\section{JOURNAL MANAGER}

Louise Pybus

\section{CONSULTANT EDITORS}

Benjamin K. Bergen

University of California, San Diego, USA

Louise Connell

Lancaster University, UK

Seana Coulson

University of California, San Diego, USA

Jennifer Culbertson

University of Edinburgh, UK

Dagmar Divjak

University of Birmingham, UK

Alessandro Duranti

University of California, Los Angeles, USA

Nick Enfield

University of Sydney, Australia

Dirk Geeraerts

University of Leuven, Belgium

Stefan Th. Gries

University of California, Santa Barbara, USA
Bernd Heine

University of Cologne, Germany

Dan Hutto

University of Wollongong, Australia

David Kemmerer

Purdue University, USA

Jean-Pierre Koenig

State University of New York, Buffalo, USA

Gitte Kristiansen

Universidad Complutense de Madrid, Spain

Laura Michaelis

University of Colorado, Boulder, USA

Aliyah Morgenstern

Université Sorbonne Nouvelle-Paris 3. France

Chris Sinha

Hunan University, China

Asli Özyürek

Radboud University, Nijmegen, The

Netherlands 